\title{
SUPPORTING THE EU RESPONSE TO ENVIRONMENTAL EMERGENCIES: EUROPEAN MULTIPLE ENVIRONMENTAL THREATS EMERGENCY NETWORK
}

\author{
LISBETH HALL ${ }^{1}$, JOLANDA ROELOFS ${ }^{1}$, SJORS SCHULPEN ${ }^{1}$, ARNOUT DE BRUIN ${ }^{1}$, SANDER BANUS ${ }^{1}$, \\ RAQUEL DUARTE-DAVIDSON ${ }^{2}$, EIRIAN THOMAS ${ }^{2}$, EMMA-JANE GOODE ${ }^{2}$, OWEN LANDEG $^{2}$, \\ ANGIE BONE ${ }^{2}$, ELISABETH WIGENSTAM ${ }^{3}$, BIRGITTA LILJEDAHL $^{3}$, ANNICA WALEIJ $^{3}$, \\ LOUISE SIMONSSON ${ }^{3} \&$ ANN GÖRANSSON NYBERG ${ }^{3}$ \\ ${ }^{1}$ National Institute for Public Health and the Environment (RIVM), The Netherlands. \\ ${ }^{2}$ Public Health England (PHE), United Kingdom. \\ ${ }^{3}$ Swedish Defence Research Agency (FOI), Sweden.
}

\begin{abstract}
The European Union (EU) has mechanisms in place to support countries when an environmental emergency strikes and it deploys experts to assist the local community. These experts may find themselves in a chaotic situation, in which local and national authorities are overwhelmed. Collating the necessary evidence from scattered sources to conduct a robust risk assessment is a major challenge and deployed experts may not have access to the necessary technical expertise.

Therefore, the European Multiple Environmental Threats Emergency Network (EMETNET) project is building a simple, efficient and robust methodology to enable the rapid risk assessment (RRA) of environmental emergencies. The RRA, which will be delivered to the European Commission (EC), presents an overview of potential and actual health and environmental impacts of the event. A network of risk assessors is being built to carry out this RRA and provide back-office support to deployed experts, enabling them to have rapid access to information and expertise. EMETNET builds on existing methodologies for the RRA of environmental emergencies, in particular, on a methodology developed for serious cross-border chemical health threats.

The EMETNET methodology will support the selection of experts and assets deployed to affected regions and provide a snapshot assessment to experts en route to disaster zones. It will aid defensible decision-making, communication, planning and risk management. Furthermore, it will ensure a harmonised understanding of the associated health, environmental and cross-sectoral impacts of an environmental emergency.

Keywords: DG ECHO, Environmental emergencies, Expert network, Impact, Natural disasters, Public health, Environment, Rapid risk assessment, Union Civil Protection Mechanism, UCPM.
\end{abstract}

\section{INTRODUCTION}

Every year the world is hit by numerous natural and manmade disasters, such as the severe mudslides in Columbia and Peru in spring 2017. Many lives are lost, the environment is badly damaged and infrastructure and livelihoods are severely disrupted. In 2015, there were 198 natural catastrophes, the highest ever recorded in one year, according to a 2016 Swiss Re sigma study [1].

EU Member States (MSs) differ in their ability to (rapidly) assess both natural and manmade disaster risks. As recognised by EU Decision 1313/2013/EU on a Union Civil Protection Mechanism (UCPM) [2] and EU Decision 1082/2013/EU on serious cross-border threats to health [3], there is a need to strengthen and improve cooperation and coordination in the fields of civil and health protection, in particular to improve the prevention, preparedness and response to natural or man-made disasters that can impact upon one or more MS.

The EU has mechanisms in place to support countries when an environmental emergency strikes and they deploy experts to the scene to assist the local community. On arrival, these experts often find themselves in the midst of a chaotic situation, in which local and perhaps 
even national authorities are overwhelmed. Collating the necessary information from scattered sources to coordinate a robust risk assessment is a major challenge. Moreover, these experts often do not have access to the technical back up and expertise they receive in their own countries.

The EMETNET project has been initiated to provide a simple, robust, inexpensive and authoritative methodology to support the EU and MSs in undertaking rapid risk and impact assessments of emerging environmental threats. This will enable a harmonised understanding of the associated health, environmental and cross-sectoral impacts of such events to aid risk management and the planning and response process. The project is building a pilot network of expert risk assessors to support the Emergency Response Coordination Centre (ERCC) within EC Directorate-General for European Civil Protection and Humanitarian Aid Operations (DG $\mathrm{ECHO}$ ) in the rapid scientific assessment of risks to inform responders in the field and to contribute to harmonised risk management. Lessons learnt from past disasters, best practise identified in previous EU-funded projects and from stakeholder engagement with other European and MS authorities will help to ensure that the proposed approach is consistent with the needs of EU and MSs.

EMETNET builds on the methodology developed for serious cross-border chemical health threats in the European Chemical Emergency Network (ECHEMNET) project co-funded by EC Directorate-General for Health and Food Safety (DG SANTE) [4].

\section{RAPID RISK ASSESSMENT OF ENVIRONMENTAL EMERGENCIES}

\subsection{Introduction to rapid risk assessment methodology}

A rapid risk assessment (RRA) methodology is being developed to address the risks from emerging environmental threats, either natural or manmade, which have the potential to cause significant damage to public health and the environment. It is based on a RRA methodology originally developed to deal with chemical incidents and poisonings that can have significant impacts on the health and wellbeing of people locally and across borders [4]. The original methodology has been adapted to deal with the broader issues relevant to natural and manmade incidents, including impacts on the natural environment. The RRA methodology provides a quick and robust means of assessing the risks associated with these threats and will be performed on request by DG ECHO/ERCC. Table 1 presents a summary of the natural and manmade hazards considered in the RRA methodology.

The methodology has been tested by using case studies of previous disasters corresponding to the hazard categories in Table 1 to ensure that all relevant information needed to estimate the risks to health and the environment has been captured.

\subsection{RRA methodology}

The RRA methodology being developed in EMETNET follows other methodologies by containing three core components: hazard assessment, exposure assessment and context assessment [5]. The RRA itself is a comprehensive template containing several sections and is designed to act as a checklist to the risk assessors to ensure all the relevant information is captured. 
Table 1: Natural and man-made hazards.

Natural Hazards [6, 7]

Weather and climate-related hazards (includes atmospheric and hydrological processes)

Drought

Extreme Temp.

Flood

Storm

Storm (Cyclonic)

Wildfire
An extended period of unusually low precipitation that produces a shortage of water for people, animals and plants and includes meteorological drought, agricultural drought, and hydrological drought.

A climatological hazard relating to heat waves, cold waves or severe winter conditions.

When water overflows or soaks land that is normally dry. This includes coastal flooding, riverine flooding, flash floods, and ice jam floods.

A period of disruptive weather most often accompanied by strong, high force winds. There are several types of storms; severe storm (thunderstorm), tornado, sand/dust storm, and severe winter storms.

Tropical storm; a rapidly rotating, cyclonic storm normally originating over tropical waters.

Any uncontrolled and non-prescribed combustion or burning of plants in a natural setting such as a forest, grassland or brush land which spreads based on environmental conditions.

Geological/ Geophysical hazards

Earthquakes

Mass movements

Tsunami

Volcanic Activity

A sudden release of built-up energy in the earth's crust usually caused by movement along a geological fault or by volcanic activity resulting in the generation of seismic waves which can sometimes be destructive.

Mass movements can be caused by rivers, heavy rain and/ or seismic activity. This includes; rock fall, landslides, lahar (made up of volcanic ash), flows, avalanches, and subsidence. A series of waves that are generated by a displacement of massive amounts of water through underwater earthquakes, volcanic eruptions, landslides or extra-terrestrial impacts. Any type of volcanic event near an opening/vent in the Earth's surface including volcanic eruptions of lava, ash, hot vapour, gas, and pyroclastic material.

\section{Biological hazards}

Harmful Organisms

The spread or infestation of an organism and its toxic substances or vector-borne diseases they may carry which can cause damage or ill health. This includes insect infestations, algal blooms, encounters with dangerous or venomous animals or plants, or the intentional or unintentional introduction of an organism into a new environment. 
Table 1: (Continued)

Natural Hazards [6, 7]

Infectious disease

Infectious diseases are caused by pathogenic microorganisms, such as bacteria, viruses, parasites or fungi; the diseases can be spread, directly or indirectly, from one person to another.

Extra-terrestrial hazards

Extra-terrestrial Impact An extra-terrestrial body such as a meteor, comet or asteroid which either impacts with the Earth's surface or explodes upon entering Earth's atmosphere.

Space Weather

A collective term for a number of physical processes which occur in space that can affect the human activities and infrastructure on Earth including energetic particles, geomagnetic storms, and solar flares.

Technical and Man-made hazards

Anthropogenic; non-intentional

Chemical

Environmental Pollution/ Contamination

Radiation

Technological disasters and Major Accidents
An unexpected uncontrolled release of a chemical from its containment.

The introduction of toxic chemicals or industrial wastes into the natural environment which may cause adverse effects. This includes air pollution, water pollution and soil pollution. The release of radioactive particles leading to exposure to the human population exceeding established safety levels.

Danger originating from technological or industrial accidents, dangerous procedures, fires and explosions, infrastructure failures or certain human activities which may cause the loss of life or injury, property damage, social and economic disruption or environmental degradation.

\section{Anthropogenic; intentional}

Wars, Conflict and Civil Threatens environment, health, safety or wellbeing of a Strife community or large group of people. This includes: mass shootings, civil disobedience, terrorism, weapons of mass destruction (chemical, biological, nuclear/radiological, explosives)

\subsubsection{Hazard Assessment}

The Hazard Assessment identifies the particular hazard(s) that have caused the event, e.g. an earthquake, and any subsequent incidents that follow as a consequence of the first hazard. For example, the earthquake has caused a landslide and the landslide has blocked a water course which has caused flooding further upstream. The hazard assessment section will identify and summarise the causal incident (i.e. earthquake), the consequential incidents (i.e. landslides, flooding) and the potential for any further incidents (i.e. major accident: a major dam is 
experiencing structural issues after seismic activity, failure might occur at some point). The hazard assessment reviews key information about the hazards, e.g. location of each of the identified and potential incidents, and ranks the potential hazards [5]. Where possible, consideration should be given to any similar events that have happened in the region, including the effectiveness of previous risk assessments and any lessons learnt.

\subsubsection{Exposure Assessment}

The Exposure Assessment evaluates the exposure and impact of the incident on individuals and the population at risk [5]. Consideration needs to be given to the number of people that are likely to be exposed to the incident, the duration of the exposure as well as how the geography of the location may impact on exposure. Within the EMETNET methodology, two sections are included which make up the exposure component of the template: Exposure and Impact Assessment, and Health Assessment. The Exposure and Impact Assessment not only captures information on the consideration above, but also identifies any critical infrastructure pertinent to the region at risk and how this could further impact the affected population and the environment. The Health Assessment evaluates the risk to health and public health of the population affected, as well as identifying any particularly vulnerable groups such as elderly, children, gender-specific or race-specific groups.

\subsubsection{Context Assessment}

A context assessment is the evaluation of the environment in which the incident has taken place and must consider all the factors that can affect the risks [5]. The RRA template contains a number of sections that make up the context assessment; Environment Assessment, Response Capacity Assessment, and Social, Economic and Cross-sectoral factors. Each section is designed to address a specific aspect of the environment in which the event has occurred. The Health Assessment can also be included under this heading as it also addresses public health issues, such as impacts of the food or water supply, impacts on waste, sanitation and the likelihood of communicable disease outbreaks.

The Environment Assessment evaluates the physical environment of the event such as the impacts on air quality, water quality, land and soil issues, i.e. land use changes, topographical changes and soil pollution, vegetation, biodiversity, protected areas and ecosystem services. Both the natural environment and the managed environment need to be considered, i.e. farms, agricultural land and livestock. The RRA methodology also allows for the use of a number of environmental assessment tools such as the Flash Environmental Assessment tool (FEAT) [8] and the Post Disaster Needs Assessment (PDNA) tool [9], and where applicable these tools can be used to help highlight and inform the risks.

The Response Capacity Assessment along with Social, Economic and Cross-sectoral factors considers the risks associated with other sectors (social, technical, ethical, economic, political, legal etc.) that will have an impact on the population and the environment. The WHO refers to this as the STEEEP analysis [5]. The impact of the event on these issues can affect the level of risk by increasing or decreasing the probability of exposure [5].

The next step in the RRA methodology is that of risk characterisation, which will estimate the likelihood and the consequences of the risk. The EMETNET RRA has adapted the risk matrices from the WHO Risk Assessment manual [5] to include more detailed criteria for estimates of consequences of the event. Within this RRA, the estimates of risk are based on expert risk assessor opinion.

Once the RRA is complete, a summary is produced containing information on the key risks identified in the section assessments above. The RRA summary is the only part of the 
document that is shared with external parties to ensure that they have access to the essential information requested, rather than detailed information of the event that is used to inform the risk assessment within the different components of the RRA. It is important to bear in mind that as the incident progresses the risk estimates may change and therefore the RRA may need to be updated accordingly. The detailed information, however, will be available through 'back-office' support and the more detailed material, sources and advice contained within the RRA document can be shared if requested by DG ECHO, ERCC or supporting experts deployed through the UCPM.

The RRA template gives an auditable and defensible trail to illustrate what the risks are and why specific steps were taken in response to a disaster. It ensures that resources are not wasted and that appropriate response measures are taken.

The RRA has been through several iterations and has been tested at two workshops: an internal workshop with the project team in Oxford UK and an external workshop in Amersfoort, Netherlands. In the external workshop, key stakeholders and experts were asked to work through the RRA using a disaster scenario and to comment on the suitability of the RRA. A command post exercise, which took place in March 2017, resulted in further suggestions for improvement. The comments and suggestions from the workshops and exercise were collated and have been used to inform further iterations of the RRA.

\section{NETWORK OF EXPERT RISK ASSESSORS}

\subsection{Network of expert risk assessors and areas of expertise}

Within the EMETNET project, a network of expert risk assessors is being built to provide rapid, dynamic and authoritative risk assessment of serious acute environmental emergencies using the methodology described in Chapter 2. The experts recruited to the network are contributing to the development of the RRA methodology and network mechanism to ensure that these are fit for purpose. They have also been invited to participate in exercises to test the network methodology and mechanism. Once sufficiently established and exercised, the network will function in 'pilot mode' during the remainder of the project duration to provide risk assessment support should a 'live' event take place.

The areas of expertise that the network needs to cover have been discussed with experts who have experience of being sent on missions (e.g. by DG ECHO/ERCC and Joint UNEP/ OCHA Environment Unit (JEU)), and with stakeholders who deal with the deployment of experts in the field (DG ECHO/ERCC and national civil protection focal points). The experts have provided information on areas of expertise they require to support their work in the field and how back-office support can best be delivered to them. Stakeholders have suggested areas of expertise they feel are required, based on the deployments they have coordinated and the terms of reference for deployed experts. The areas of expertise required in the network were further explored during an interactive session at a project workshop in November 2016 using a scenario based on a combination of hazards listed in Table 1 (storms, earthquakes and floods). The areas of expertise which have been recognised so far as those which the network should ideally cover are shown in Table 2 , with those areas of expertise covered by the experts already in the network being highlighted in grey.

For recruitment purposes, a questionnaire has been developed for potential members of the network of experts to complete, including an expertise framework with tick boxes based on the areas of expertise defined during the aforementioned process. The questionnaire includes 
Table 2: Areas of expertise which the EMETNET network should ideally cover and those currently available among experts within the network (highlighted in grey).

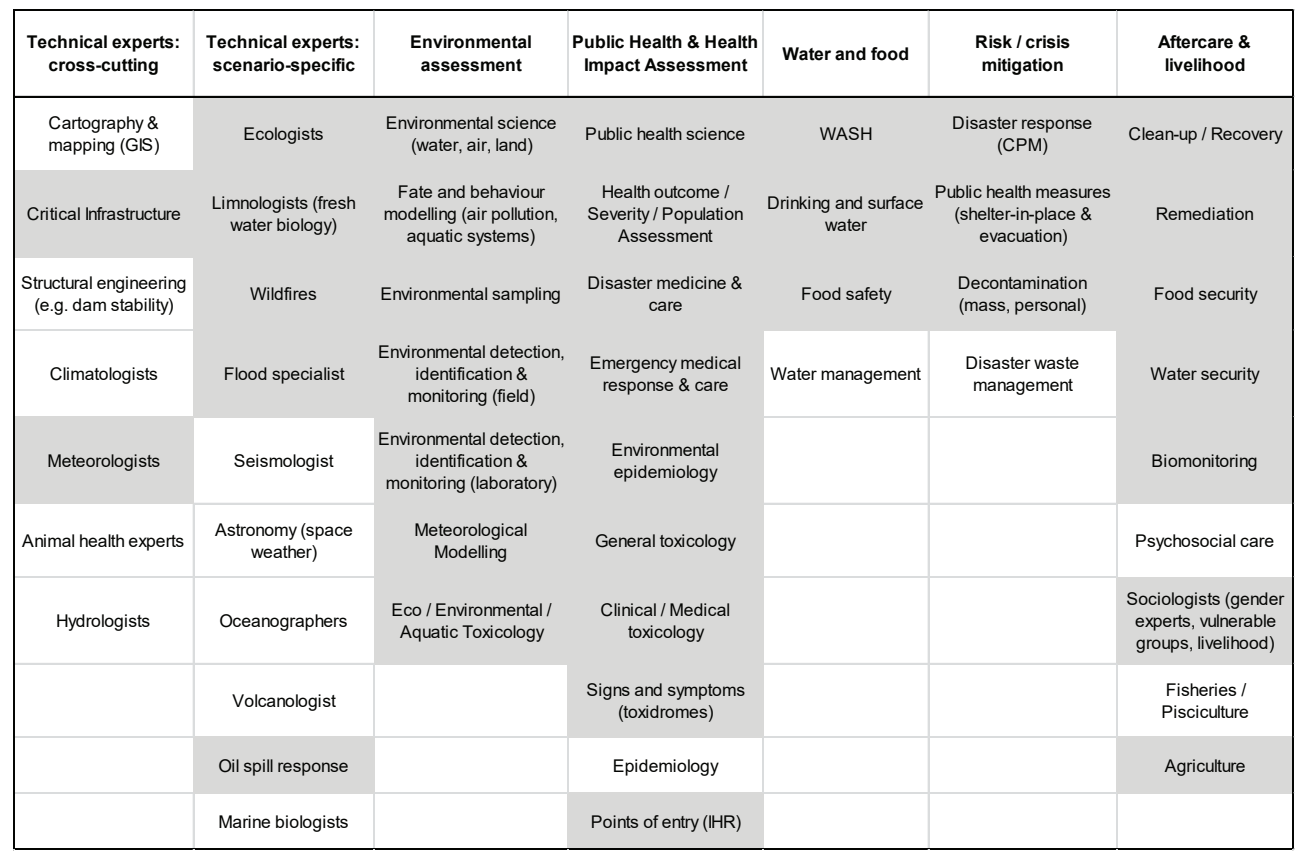

inter alia questions to elucidate the level and range of experience of the risk assessors, especially in the acute phase of an incident/disaster. This questionnaire has been sent to experts identified by project partners and their networks as having the expertise necessary for the network. Identifying and inviting experts with areas of expertise needed within the network is an ongoing process throughout the project.

\subsection{Current proposed structure of the EMETNET network}

Discussions are ongoing with DG ECHO/ERCC to ascertain the structure and mechanism whereby the RRA and back-office support can best be delivered and to ensure the sustainability of the network and the RRA methodology beyond the life of the project. The currently envisaged lines of communication of the network are shown in Figure 1, including the RRA delivery chain.

\section{LESSONS LEARNT FROM PAST DISASTERS AND EXERCISES}

\subsection{Introduction}

An analysis of lessons learnt from past disasters is being conducted to test and improve the design of the RRA. This includes the identification and evaluation of knowledge gaps and issues that have lacked attention in the acute phase of environmental emergencies. Due consideration of these knowledge gaps and issues would help improve response and crisis management, and would increase the possibilities of a sustainable recovery. To complement 


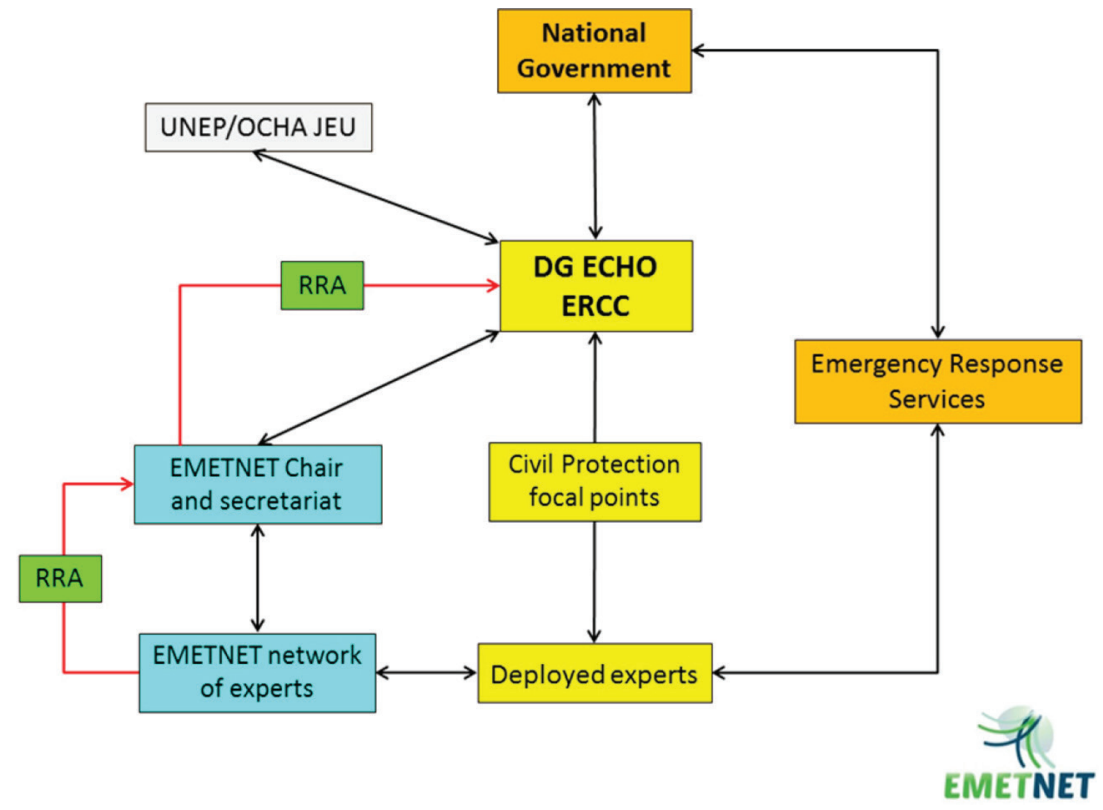

Figure 1: Proposed structure of EMETNET network response and lines of communication (black arrows $=$ proposed lines of communication; red arrows $=$ RRA delivery chain).

this work, exercises are being held in which experts actively test and evaluate the RRA using a scenario that has been formulated based on the work on identifying emerging environmental threats and lessons learnt from past disaster events.

\subsection{The European Union Civil Protection Mechanism and environmental emergencies}

The Union Civil Protection Mechanism (UCPM) aims to strengthen the cooperation between the EU and the MSs and to facilitate coordination in the field of civil protection in order to improve the effectiveness of systems for preventing, preparing for and responding to natural and man-made disasters [2]. The protection under the UCPM primarily covers people, but also the environment and property against all kinds of natural and man-made disasters, including environmental disasters, marine pollution and acute health emergencies, occurring inside or outside the EU [2]. The UCPM has been activated for a number of such events.

From January 2007 to March 2016, 49\% of UCPM activations took place in Europe. Table 3 lists the five most common reasons for activation of the UCPM worldwide and in Europe. Forest fires caused the most activations; both within and outside Europe, with floods and severe weather also frequently triggering the UCPM worldwide. Earthquakes, on the other hand, are a fairly common reason for activation outside Europe but somewhat less common in Europe, whereas activations due to marine pollutions and explosions (e.g. ammunition storage sites) were more common in Europe.

Interesting to note is that activations due to a need to respond to civil unrest related to the refugee crises have increased in the past few years. In 2016 alone, civil unrest, conflict and displaced persons accounted for 17\% of the UCPM activations, only exceeded by forest fires (25\%) and followed by earthquakes and storms (14\% each). 
Table 3: Some of the most common reasons for activation of the UCPM from January 2007 to March 2016. [10]

Worldwide (total number: 287)

Europe (total number: 142)

Forest fires (60)

Forest fires (35)

Severe weather* (53)

Floods (27)

Floods (50)

Severe weather* (13)

Conflict/refugees (31)

Marine pollution and explosions (9)

Earthquakes (23)

Refugee crises (9)

* i.e. storms, cyclones, typhoons, etc.

\subsection{Selection of cases for lessons learnt}

As the purpose of the EMETNET project is to support DG ECHO and ERCC, events that have triggered the activation of the UCPM have been selected from the UCPM database. By examining these events, the UCPM response itself can also be evaluated as well as how and if the EMETNET RRA could support the mechanism.

Selection of event types to study further includes forest fires, floods, earthquakes, extreme weather, conflict/refugee situations and NaTech accidents (Natural Hazards Triggering Technological Accidents). The criteria for selection of cases to study in depth are based on the following factors: type of event, temporal and spatial coverage, effect on human health, the environment and social, economic and political impact. The cases should represent major causes of disasters in Europe and globally and ideally also be emerging, that is, show a future trend of an increase in these types of disasters. Disaster events are, however, often case specific and context-bound, which is why the decision on the number and types of cases to include needs to be made cautiously. Also challenging for the analysis is that extreme events are rare, which means there are few data available to make assessments regarding changes in their frequency or intensity. The more rare the event, the more difficult it is to identify long-term changes. Global-scale trends in a specific extreme event may be either more reliable (e.g. for temperature extremes) or less reliable (e.g. for storms) than some regional-scale trends, depending on the geographical uniformity of the trends in the specific extreme event.

\subsection{Initial observations}

Although the evaluations of lessons learnt is ongoing, some generic observations can be identified which are described in more detail below.

\subsubsection{Lessons on response triggers}

It is not necessarily the most common events or the events that result in most human suffering or casualties that generate response activities. For instance, of the response activities performed by JEU in 2004-2014, 38\% addressed manmade and/or technological disasters. In addition, preparedness and capacity development for such events accounted for $22 \%$.

There are no records of droughts in the UCPM database, even though the EM-DAT database run by the Belgian-based Centre for Research on the Epidemiology of Disasters (CRED) recorded 136 drought events in Africa alone between 1995 and 2015 [6]. Droughts 
generally affect a very large number of people and the CRED recommendation is that there needs to be improved data collection on indirect deaths from droughts [11].

\subsubsection{Lessons on key determinants of disaster risk and impacts}

Disasters are not neutral. Recovery interventions are not neutral either since they can increase, reinforce or reduce existing inequalities. Recovery interventions may hence have a negative impact on gender roles, poverty, the environment and the livelihoods of vulnerable groups [12]. One example is the 2004 tsunami, when recovery aid was concentrated on the fishing sector but not so much on the informal sector, agriculture or business. Within the fishing sector, it was the fishermen who got assistance, rather than women who traded the fish [13].

An understanding of exposure and vulnerability as key determinants of disaster risk and of impacts is critical. For instance, a tropical cyclone can have very different impacts depending on where and when it makes landfall. Similarly, a heat wave can have very different impacts on different groups of populations depending on their vulnerability. Severe impacts can also result from non-extreme events where exposure and vulnerability are high or from a compounding of events or their impacts.

\subsubsection{Lessons on secondary impacts}

Environmental degradation, deforestation and soil erosion are common vulnerability and sensitivity factors which worsen the impacts of natural disasters. Insufficient attention to environmental considerations can trigger significant degradation and secondary impacts for populations and decreasing socio-ecological resilience. Despite attempts from several organisations to highlight the environmental challenges for upcoming crisis response efforts, very few mechanisms to mainstream this knowledge into the execution of the responses have been implemented [14].

The risks of infectious disease outbreaks following natural disasters are often raised but are generally overstated and lead to misallocation of resources. The overwhelming number of deaths immediately after a natural disaster are directly associated with blunt trauma, crushrelated injuries and burn injuries. No certain risk of an infectious disease epidemic occurring in the short-term period after a disaster has been well documented [15]. Flooding is the most common natural disaster described with an increase in cases or outbreaks of infectious diseases, such as diarrhoea, malaria and leptospirosis, whereas a 2006 review showed that only three out of 600 geophysical disasters led to disease epidemics [16]. In fact, the real risk posed by e.g. handling dead bodies is physiological stress caused by grief and shock [17]. Rather, the risk factors for disease outbreaks after disasters are associated primarily with population displacement. The availability of potable water and sanitation, the degree of crowding, the underlying health status of the population, and the availability of healthcare services all interact within the context of the local disease ecology to influence the risk for communicable diseases and death in the affected population [18].

\subsubsection{Lessons on the local and cultural context}

The inability of international response teams to adapt to the cultural and social contexts in the affected countries can have grave consequences. For instance, the response to the Ebola crisis in West Africa created a significant resistance among the population towards the response since it was too technical and medical in nature and lacked cultural, psychological and sociological understanding [19]. In fact, the majority of life-saving work in any disaster is 
done by the local populations themselves. Agencies must give good information to communities so they can plan their own recovery from the start.

Another lesson is that recovery is the overriding challenge whereas the need for relief has often been overstated. Recovery also includes social, political, economic and environmental dimensions - not just physical security - and there is a limit to what humanitarian assistance can do. Sustainable livelihoods are key to recovery and it is paramount to listen to affected people about their priorities for livelihood recovery which is often closely linked to the environment and ecosystem services.

\subsection{Reflections on 'lessons learnt'}

Lessons learnt is an expression that implies that one actually has learnt something as well as implemented new knowledge in crisis management procedures. However, the need to produce results in the field and report back that a mission has been successful to ensure future funding may emerge as an unintended obstacle. This impacts both the possibility for efficient coordination and the problem of a lack of 'true' reporting on failures [20]. One such example is the evaluation of the humanitarian response to earthquakes, which has concluded that emergency responses have not effectively applied lessons from previous emergencies [21]. Another example is provided by water and sanitation (WASH) interventions which frequently fail, although the results are not necessarily reported as such [22]. Examples where toilets are left unused because the affected communities did not realise they were built for them are all too common.

\subsection{Exercises}

Within the EMETNET project, two exercises are being held. As described previously, the main objectives of these exercises are to apply lessons learnt from previous disasters, test the RRA methodology and ensure it is fit for purpose, and test the activation and function of the expert network. Both exercises are run in real-time and are of command-post character, i.e. the players work from their normal workplaces with access to all communication tools via internet and/or telephone lines.

The first exercise was run on 21st March 2017. Fourteen participants from the Netherlands, UK, Sweden and Slovenia joined and were assigned to perform a RRA for a major heat wave in Europe with resulting cascading events. The expert risk assessors managed to deliver answers to critical questions using the RRA template, despite the lack of expertise in some technical areas and reported back to exercise control with a thorough report of the incident(s). A quick wash-up immediately after the exercise showed that participants generally felt it was a successful exercise. They found it challenging with regards to the assignment and the time limit and some found it hard to manage the documents on the collaboration platform used. Nevertheless, they felt the collaboration within the network went well and they were satisfied with the assessments they produced.

\section{CONCLUSIONS}

Within the EMETNET project, a network of experts is being built to carry out a rapid risk assessment (RRA) and provide back-office support to experts deployed to an environmental emergency. So far, the network covers a number of the defined areas of expertise. Recruitment of network members is ongoing to cover more areas of expertise and to ensure resilience of the 
network. The RRA methodology being developed has been tested and exercised with promising results. During the first exercise, the network successfully collaborated remotely to carry out a number or RRAs in response to a complex scenario. During the coming year, the network will be further tested and exercised and a structure for a sustainable network response beyond the life of the project will be explored. From the analysis of lessons learnt, it is clear that accountability to the affected people and honest assessment of true lessons learnt is of real importance. Translating these lessons into doable actions is a collective responsibility for all emergency response actors and can help ensure the success of emergency response.

\section{ACKNOWLEDGEMENTS}

The project partners, RIVM, PHE and FOI, are grateful to the EU Civil Protection Financial Instrument for the co-funding of this project (Grant Agreement No. ECHO/SUB/2015/718592/ PREV14).

\section{REFERENCES}

[1] Bevere, L., Sharan, R. \& Vipin, K., Natural catastrophes and man-made disasters in 2015: Asia suffers substantial losses. Swiss Re sigma no. 1/2016

[2] European Parliament and Council. Decision No. 1313/2013/EU of the European Parliament and of the Council of 17 December 2013 on a Union Civil Protection Mechanism. Official Journal of the European Union. L 347, pp. 924-927, 2013. Available at: http://eur-lex.europa.eu/LexUriServ/LexUriServ.do?uri=OJ:L:2013:347:0924: 0947:EN:PDF. (accessed 3 April, 2017).

[3] European Parliament and Council. Decision No. 1082/2013/EU of the European Parliament and of the Council of 22 October 2013 on serious cross-border threats to health and repealing Decision No 2119/98/EC. Official Journal of the European Union. L 293 05.11.2013; 1-15. Available at: http://eur-lex.europa.eu/ LexUriServ/LexUriServ. do?uri=OJ:L:2013:293:0001:0015:EN:PDF. (accessed 3 April, 2017).

[4] Orford, R., Hague, C., Schapers, A., Hall, L., Roelofs, J., Morgenstern, P., Göranssen Nyberg, A., Wigenstam, E., Trnka, J., García Cazalilla, M., Ocaña García-Donas, J. \& Duarte-Davidson, R., European Chemical Emergency Network (ECHEMNET): dealing with serious cross border chemical health threats. In preparation.

[5] World Health Organization. Rapid Risk Assessment of Acute Public Health Events, 2012. Available at http://www.who.int/csr/resources/publications/HSE_GAR_ARO_2012_1/ en/. (accessed 15 March, 2017).

[6] Centre for Research on the Epidemiology of Disasters. EM-DAT: The International Disaster Database. Available at http://www.emdat.be. (accessed 15 March, 2017).

[7] International Federation of Red Cross and Red Crescent Societies. Types of disasters: Definition of hazard. Available at http://www.ifrc.org/en/what-we-do/disaster-management/about-disasters/definition-of-hazard/. (accessed 15 March, 2017).

[8] Joint UNEP/OCHA Environment Unit. The Flash Environmental Assessment Tool (FEAT) v2.0. 2016. Available at https://docs.unocha.org/sites/dms/ Documents/FEAT_ pocket_final.pdf. (accessed 15 March, 2017).

[9] International Recovery Platform. Post Disaster Needs Assessment, 2008. Available at http://www.recoveryplatform.org/pdna/. (accessed 15 March, 2017).

[10] European Community Civil Protection Mechanism Activations overview 01.01.2007 01.05.2016, on file with authors. 
[11] Centre for Research on the Epidemiology of Disasters (CRED) and United Nations Office for Disaster Risk Reduction (UNISDR). The human cost of weather-related disasters 1995-2015, 2015.

[12] Neumayer, E. \& Plümper, T., The gendered nature of natural disasters: the impact of catastrophic events on the gender gap in life expectancy, 1981-2002. Annals of the Association of American Geographers, 97(3), pp. 551-566, 2007. https://doi.org/10.1111/j.1467-8306.2007.00563.x

[13] ActionAid. Tsunami response: a human rights assessment. London: ActionAid International, 2006.

[14] Abrahams, D., The barriers to environmental sustainability in post-disaster settings: a case study of transitional shelter implementation in Haiti. Disasters, 38(s1), pp. S25-S49, 2014. https://doi.org/10.1111/disa.12054

[15] Kouadio, I., Aljunid, S., Kamigaki, T., Hammad, K. \& Oshitani, H., Infectious diseases following natural disasters: prevention and control measures. Expert Review of AntiInfective Therapy, 10(1), pp. 95-104, 2012. https://doi.org/10.1586/eri.11.155

[16] Floret, N., Viel, J-F., Mauny, F., Hoen, B. \& Piarroux, R., Negligible risk for epidemics after geophysical disasters. Emerging Infectious Diseases, 12(4), pp. 543-548, 2006. https://doi.org/10.3201/eid1204.051569

[17] de Ville de Goyet, C., Epidemics caused by dead bodies: a disaster myth that does not want to die. Revista Panamericana de Salud Pública, 15(5), pp. 297-299, 2004. https://doi.org/10.1590/s1020-49892004000500002

[18] Watson, J.T., Gayer, M. \& Connolly, M.A., Epidemics after natural disasters. Emerging Infectious Diseases, 13(1), pp. 1-5, 2007. https://doi.org/10.3201/eid1301.060779

[19] Leach, M., Time to put Ebola in context. Bulletin of the World Health Organization, 88(7), 481-560, 2010.

[20] Waleij, A. \& Liljedahl, B., The gap between the buzz words and excellent performance; lessons drawn from the environmental footprint from military and civilian actors in crises and conflict settings. Prepared for the Environmental Dimensions of Sustainable Recovery: Learning from Post-Conflict and Disaster Response Experience Project. FOI-R-4246-SE. Stockholm, Sweden, 2016.

[21] Cosgrave, J., Responding to earthquakes 2008: Learning from earthquake relief and recovery operations. ALNAP Lessons Papers, 2008. Available at: http://www.alnap.org/ resource/5239. (accessed 3 April, 2017).

[22] James, J., Analysis: Sanitizing the truth - when WASH fails. IRIN News, 17 September 2013. 